\title{
Umedecimento do substrato, temperatura na germinação e vigor de sementes de Bixa orellana $\mathbf{L}$
}

\author{
Moistening of the substract, temperature on the germination and vigor of Bixa orellana \\ L. seeds
}

\section{Fábio Henrique Morais de Sousal, Jéssica Nepomuceno Patriota², Diógenis Fontenele Ferreira Júnior³, Lucicléia Mendes de} Oliveira ${ }^{4}$ Priscila Bezerra de Souza ${ }^{5}$

Resumo: A Bixa orellana L., é uma planta originária da América Tropical, pertencente à família Bixaceae, cujos frutos são cápsulas recobertas de espinhos, ovóides que contém em torno de 40 a 50 sementes e possuem um pigmento natural muito utilizado na indústria alimentícia. Estudos sobre a germinação do urucum são essenciais para otimizar a propagação sexuada, em relação a temperatura e ao volume de água no substrato, papel toalha Germitest, que melhor expresse a germinação . O objetivo foi avaliar diferentes volumes de água para o umedecimento do substrato e temperatura na germinação e vigor de sementes de Bixa orellana L. O experimento foi desenvolvido no Laboratório de Análise de Sementes da Universidade Federal do Tocantins-UFT, campus de Gurupi (TO) avaliando parâmetros de germinação, sementes mortas, o Índice de velocidade de germinação, crescimento e massa seca de plântulas em delineamento inteiramente casualizado no esquema fatorial $2 \times 4$ (temperaturas e volumes de água), com quatro repetições de 25 sementes para cada tratamento. O tratamento para superação de dormência pode não ter sido eficaz devido à baixa porcentagem de germinação das sementes nas duas temperaturas, sendo que a $30^{\circ} \mathrm{C}$ foram observados os melhores resultados. Na temperatura de $25^{\circ} \mathrm{C}$ esses valores variaram de 13 a $19 \%$ e de 18 a $29 \%$ na de $30^{\circ} \mathrm{C}$. O teste de massa seca sugere que quantidades de água superior a 2,5 vezes ao peso seco do substrato papel podem afetar negativamente o vigor e substrato pouco umedecido limita a germinação das sementes.

Palavras-chaves: Urucum, crescimento, volumes de água.

Abstract: The Bixa orellana L., is a native plant of the Tropical America, belonging to the family Bixaceae, whose fruits are capsules covered with thorns, ovoids that contains around 40 to 50 seeds and possess a natural pigment much used in the food industry. Studies on germination are essential to optimize annatto sexual propagation in relation to temperature and volume of water in Germitest paper towel substrate that best expresses the germination. The objective was evaluate different volumes of water for the moistening of the substract and temperature in the germination and vigor of Bixa orellana L. seeds. The experiment was developed in the Seeds Analysis Laboratory of the Federal University of the Tocantins - UFT, campus of Gurupi (TO) evaluating parameters of germination, dead seeds, the germination speed index, growth and dry batter of seedlings a completely randomized design in a $2 \times 4$ factorial design (temperatures and water volumes), with four replications of 25 seeds for each treatment. The treatment for overcoming of dorrmancy may not have been efficient due to the low percentage of germination of the seeds in the two temperatures, being that to $30^{\circ} \mathrm{C}$ were observed the best results. In the temperature of $25^{\circ} \mathrm{C}$ those values varied of 13 to $19 \%$ and of 18 to $29 \%$ in the of $30^{\circ} \mathrm{C}$. The test of dry batter suggests that water quantities exceeding 2,5 times to the dry weight of the substract paper can affect negatively the vigor and substract little moistened limits the germination of the seeds.

Key words: Annatto, growth, water volumes

\footnotetext{
*Autor para correspondência

Recebido para publicação em 24/09/2014; aprovado em 10/04/2015

${ }^{1}$ Mestrando em Ciências Florestais e Ambientais, Universidade Federal do Tocantins, Gurupi-TO; (63)81345276, Email. fhms17@ hotmail.com.

${ }^{2}$ Mestranda em Ciências Florestais e Ambientais, Universidade Federal do Tocantins, Gurupi-TO, E-mail: jessica_pgt@ hotmail.com

${ }^{3}$ Mestrando em Ciências Florestais e Ambientais, Universidade Federal do Tocantins, Gurupi-TO, E-mail: diogenis@mail.uft.edu.br

${ }^{4}$ Bióloga, Dr. em Ciência \& Tecnologia de Sementes, Bolsista PNPD, Universidade Federal do Tocantins, Gurupi, TO. E-mail: lucicleia@biologa.bio.br

${ }^{5}$ Prof $^{a}$ Dr $^{\mathrm{a}}$ do Programa de Pós-graduação em Ciências Florestais e Ambientais, Universidade Federal do Tocantins, Gurupi-TO, E-mail:

priscilauft@uft.edu.br
} 


\section{INTRODUÇÃO}

A Bixa orellana L., conhecida popularmente como urucum, é uma planta originária da América Tropical, pertencente à família Bixaceae (CASTRO et al, 2009), muito utilizada na culinária e na indústria alimentícia em forma de corante natural devido sua pigmentação possuir uma substância química chamada carotenóide, conhecido como bixina, encontrado no arilo de suas sementes (CORLETT et al., 2007).

É um dos poucos produtos naturais permitidos pela Organização Mundial de Saúde sendo que cerca de $90 \%$ dos corantes naturais mais usados pelas indústrias no Brasil e no mundo o urucum é o mais empregado por não apresentar toxicidade e ser indicada como agente hipolipidêmico (SILVA et al., 2006).

Os frutos do urucum são cápsulas recobertas de espinhos, ovóides ou globulosas de 3 a $4 \mathrm{~cm}$ de comprimento e 3 a $4,5 \mathrm{~cm}$ de diâmetro, contendo em média de 40 a 50 sementes, envoltos por uma polpa de cor vermelha (FRANCO et al., 2002).

A busca de conhecimentos sobre as condições ótimas para os testes de germinação de sementes que constituem a via de propagação mais empregada na instalação de plantios, principalmente, no que se refere aos efeitos da temperatura e do substrato, determina papel fundamental dentro da pesquisa científica para fornecer informações importantes sobre a propagação e fisiologia das espécies (VARELA et al., 2005).

Neste estudo será dada ênfase quanto à temperatura e umedecimento do substrato, visto que a temperatura exerce grande influência sobre a velocidade e porcentagem final da germinação além das reações bioquímicas que determinam o processo germinativo, pois há uma sequência programada de reações químicas cujos sistemas enzimáticos apresentam exigências térmicas próprias (MARCOS FILHO, 2005).

Em relação à umidade do substrato em que não haja disponibilidade hídrica suficiente o processo de germinação pode ser seriamente prejudicado, ocasionando à morte do embrião, caso ocorra o excesso de água no substrato o processo germinativo pode ficar prejudicado devido à menor aeração (MARCOS FILHO, 2005).

A adição subsequente de água durante o teste de germinação, embora seja recomendada, deve ser evitada sempre que possível, pois pode provocar um aumento na variabilidade entre as repetições e entre os testes (COIMBRA et al., 2007), portanto, devem ser observados diariamente os substratos e adicionar água somente em casos extremos.

A padronização do volume de água que favoreça a germinação conforme a espécie, provavelmente, minimizará as variações nos resultados dos testes de germinação, neste sentido, pesquisas sobre as exigências de água em sementes são pioneiras, sendo disponíveis poucas informações sobre algumas espécies florestais, como: Dinizia excelsa Ducke (VARELA et al., 2005), Ochroma pyramidale (Cav. exLam.) Urban (RAMOS et al., 2006), Schizolobium amazonicum Huber ex Ducke (RAMOS et al., 2006).

Segundo Guedes et al. (2010) o umedecimento do substrato pode fornecer respostas eficazes no planejamento para recuperação de áreas degradadas por considerar os fatores ecológicos da espécie, indicando se as mesmas serão implantadas em áreas de clareiras, com menor disponibilidade hídrica, ou mais sombreadas, com maior disponibilidade hídrica.

Diante do exposto, estudos sobre a germinação do urucum são essenciais para otimizar a propagação sexuada, tendo em vista a padronização do teste com relação ao volume de água a ser adicionado no substrato e a temperatura que melhor expresse a germinação para minimizar as variações nos resultados deste teste.

Dada a importância com relação à quantidade de água e a temperatura para o desenvolvimento das plântulas, este trabalho teve por objetivo avaliar diferentes volumes de água para o umedecimento do substrato e temperatura na germinação e vigor de sementes de Bixa orellana $\mathrm{L}$.

\section{MATERIAL E MÉTODOS}

O experimento foi desenvolvido no Laboratório de Análise de Sementes da Universidade Federal do TocantinsUFT, campus de Gurupi (TO). Inicialmente foi realizada a coleta dos frutos em duas árvores matrizes da UFT, posteriormente foram acondicionados em sacos de papel e levados para o laboratório para serem beneficiados. O delineamento experimental foi inteiramente casualizado em esquema fatorial $2 \times 4$ (temperaturas e volumes de água), com quatro repetições de 25 sementes para cada tratamento.

Em seguida, as sementes foram submetidas ao tratamento de superação de dormência com ácido sulfúrico concentrado por 13 min $27 \mathrm{~s}$ baseado no estudo feito por Amaral et al. (1995), logo após foram submetidas aos seguintes testes:

Germinação - as sementes foram distribuídas no substrato papel toalha tipo Germitest, previamente umedecido com volumes de água equivalentes a 1,5, 2,0, 2,5 e 3,0 vezes o peso do substrato seco, sem adição posterior de água, sendo confeccionados na forma de rolo. Para cada tratamento, utilizaram-se quatro repetições de 25 sementes. Os rolos foram acondicionados em sacos de plástico transparente, para evitar a perda de água por evaporação. Esse teste foi conduzido em dois germinadores tipo B.O.D. regulados um a temperatura constante de $25^{\circ} \mathrm{C}$ e outro a $30^{\circ} \mathrm{C}$. As avaliações foram efetuadas diariamente após a instalação do teste, por um período de 21 dias, quando o experimento foi encerrado, considerando como sementes germinadas aquelas que emitiram a raiz primária e a parte aéreas aparentemente sadias, maior ou igual a cinco milímetros (PEREIRA, 1995) e também contabilizadas a porcentagem de sementes mortas.

Índice de velocidade de germinação - a contagem diária do número de sementes germinadas, adotando como critério a protrusão de raiz primária maior ou igual a cinco milímetros de comprimento (PEREIRA, 1995), sendo avaliadas conjuntamente com o teste de germinação através de contagens diárias, durante 21 dias. Para o cálculo do índice de velocidade de germinação foi empregada à fórmula de Maguire (1962):

$\mathrm{IVG}=\mathrm{G} 1 / \mathrm{N} 1+\mathrm{G} 2 / \mathrm{N} 2+\ldots+\mathrm{Gn} / \mathrm{Nn}$,

Sendo:

IVG = índice de velocidade de germinação; G1, G2, Gn = número de sementes germinadas computadas em cada contagem e $\mathrm{N} 1, \mathrm{~N} 2, \mathrm{Nn}$ = número de dias, em relação à data da semeadura.

No final do teste de germinação, aos 21 dias, foi avaliado também o crescimento das plântulas por meio do 
comprimento do hipocótilo e da raiz principal das plântulas normais de cada repetição, medidas com uma régua graduada em centímetros, sendo os resultados expressos em $\mathrm{cm} /$ plântula.

Para a determinação da massa seca de plântulas foram utilizadas as mesmas plântulas da avaliação anterior, após medidas foram colocadas em sacos de papel Kraft e levados à estufa regulada a $65{ }^{\circ} \mathrm{C}$ até atingir peso constante e, posteriormente, as amostras foram pesadas em balança analítica, sendo o peso obtido, por repetição, dividido pelo número total de plântulas normais, com os resultados expressos em g/plântula.

Para análise dos resultados estes foram submetidos à regressão utilizando o programa Assistat 7.7 beta. $\mathrm{O}$ modelo de regressão escolhido foi baseado na significância dos coeficientes da equação de regressão e no coeficiente de determinação, adotando-se $5 \%$ de probabilidade.

\section{RESULTADOS E DISCUSSÃO}

Os resultados de porcentagem de germinação encontram-se na Figura 1, de acordo com as temperaturas e volumes de água no substrato para as sementes de B. orellana L., obtidos através da submissão das mesmas às temperaturas de 25 e $30{ }^{\circ} \mathrm{C}$ e a diferentes volumes de água, indicando que as interações entre esses fatores exerceram baixa influência sobre as porcentagens de germinação das sementes.

Com o aumento da quantidade de água adicionada no substrato foi observado aumentos na porcentagem de germinação das sementes, sendo observada uma variação nos valores de 13 a $19 \%$ na temperatura de $25^{\circ} \mathrm{C}$ e de 18 a $29 \%$ na temperatura $30^{\circ} \mathrm{C}$. Devido às sementes apresentarem tegumento impermeável foi necessário realizar um tratamento pré-germinativo para superar a dormência, mas pelos resultados infere-se que o mesmo não se mostrou eficaz, provavelmente por isso, a quantidade de sementes germinadas tenha sido muito baixa para ambas as temperaturas, mesmo assim, foi possível verificar na temperatura $30^{\circ} \mathrm{C}$ resultados mais expressivos.
Estes resultados não corroboram com os mencionados por Varela et al. (2005), para Dinizia excelsa Ducke; segundo os quais os diferentes volumes de água no substrato não interferiram significativamente nas porcentagens de germinação, em razão do tratamento de dormência ter sido eficaz e que possivelmente toleram maior amplitude de faixa de volume de água.

$\mathrm{Na}$ temperatura de $25^{\circ} \mathrm{C}$ as porcentagens de germinação forem melhores nos mesmos volumes de 2,0 e 3,0 vezes o peso do papel com $18 \%$ e $19 \%$ respectivamente. As porcentagens de germinação na temperatura de $30^{\circ} \mathrm{C}$ foram maiores em relação à de $25^{\circ} \mathrm{C}$, sendo eles mais expressivos nos volumes de 2,0 e 3,0 vezes a massa do papel com $28 \%$ e $29 \%$ de germinação, respectivamente. Em ambas as temperaturas foi verificado que o volume de 1,5 é insuficiente para condução do teste de germinação tendo em vista que a espécie $B$. orellana L. requer volumes maiores de água para desencadear o processo germinativo.

Embora não tenha se encaixado em um modelo estatístico sendo não significativo ao teste de regressão nos dois tratamentos, a temperatura de $30^{\circ} \mathrm{C}$ foi mais eficiente que a de $25^{\circ} \mathrm{C}$, com média de $25 \%$ e $17 \%$ respectivamente na germinação. Picolotto et al. (2013) avaliando a expressão do potencial de germinação das sementes de urucum sob diferentes tratamentos pré-germinativos e regimes de temperatura constataram que mesmo superando a dormência, a espécie ainda apresenta baixa germinação, cujos valores variaram de 56 a $57 \%$ ao utilizar o ácido sulfúrico, sendo estes o melhores resultados na temperaturas de 25 e $30^{\circ} \mathrm{C}$. No entanto, no presente o potencial de germinação de sementes foi ainda menor.

Presume-se que o tratamento para quebra de dormência não foi eficaz, pois a propagação sexuada desta espécie é dificultada pela impermeabilidade do tegumento dificultando assim a absorção de água pelas sementes para desencadear a germinação (AMARAL et al., 1995; CUSTÓDIO et al., 2002; LOPES et al., 2008), além disso, outro fator possivelmente determinante da baixa capacidade germinativa dessa cultura seja a baixa viabilidade das sementes conforme observado por Picolotto et al. (2013).

Figura 1 - Germinação de sementes de Bixa orellana L., submetidas a diferentes temperaturas e volumes de água no substrato. ns Não Significativo.

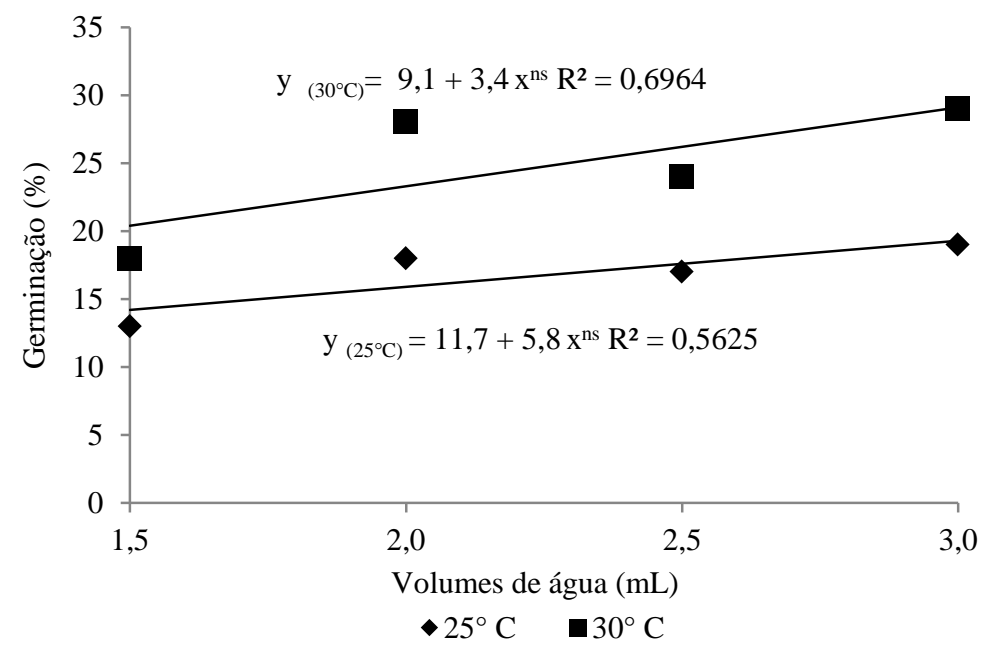


Avaliando a qualidade fisiológica das sementes na temperatura de $30^{\circ} \mathrm{C}$ através do índice de velocidade de germinação (IVG) verificou-se uma tendência de aumento na velocidade de germinação à medida que se aumentava o volume de água utilizado para umedecer o substrato (Figura 2), enquanto na temperatura $25{ }^{\circ} \mathrm{C}$ não tendo sido significativo em nenhum modelo de regressão, esse aumento foi menos pronunciado, sendo observado o maior IVG quando foi adicionado o volume de água igual a 3,0 vezes o peso do papel seco, cujos resultados apresentam comportamento semelhante ao verificado no teste de germinação para ambas as temperaturas.

$\mathrm{Na}$ temperatura de $30{ }^{\circ} \mathrm{C}$ houve uma maior velocidade de embebição da água, com o rápido amolecimento do tegumento e subsequente protrusão da radícula, caracterizando a condição ideal para desencadear o processo germinativo e o estabelecimento das plântulas. Enquanto a temperatura de $25^{\circ} \mathrm{C}$ deve ter sido insuficiente para ativar as reações metabólicas, provavelmente, por isso a porcentagem de germinação e a velocidade de germinação foram inferiores ao verificado na temperatura $30^{\circ} \mathrm{C}$.

Fato este em que os autores Mendes et al. (2006) afirmam que o tegumento rígido vem a caracterizar a dormência física, o que causa a inibição da absorção de água em sementes intactas impedindo-as que desenvolva plântulas normais. Pois a água amolece o tegumento e dá início a retomada do crescimento do embrião e, os tecidos de reserva facilitam a ruptura do tegumento e posterior protusão da raiz principal, sendo que as temperaturas mais altas favorecem a taxa e velocidade de germinação, porém só as vigorosas conseguem germinar.

Resultados estes obtidos nesse tratamento na temperatura de $30{ }^{\circ} \mathrm{C}$ que corroboram com os conseguidos por Ramos et al. (2006) para sementes de Schizolobium amazonicum Huber ex Ducke em que o índice de velocidade de germinação foi influenciado pela temperatura e volume de água no substrato

Figura 2. Índice de velocidade de germinação de sementes de Bixa orellana L. em diferentes temperaturas e volumes de água no substrato. $*=\mathrm{P}<0,05 ;{ }^{\text {ns }}$ Não significativo.

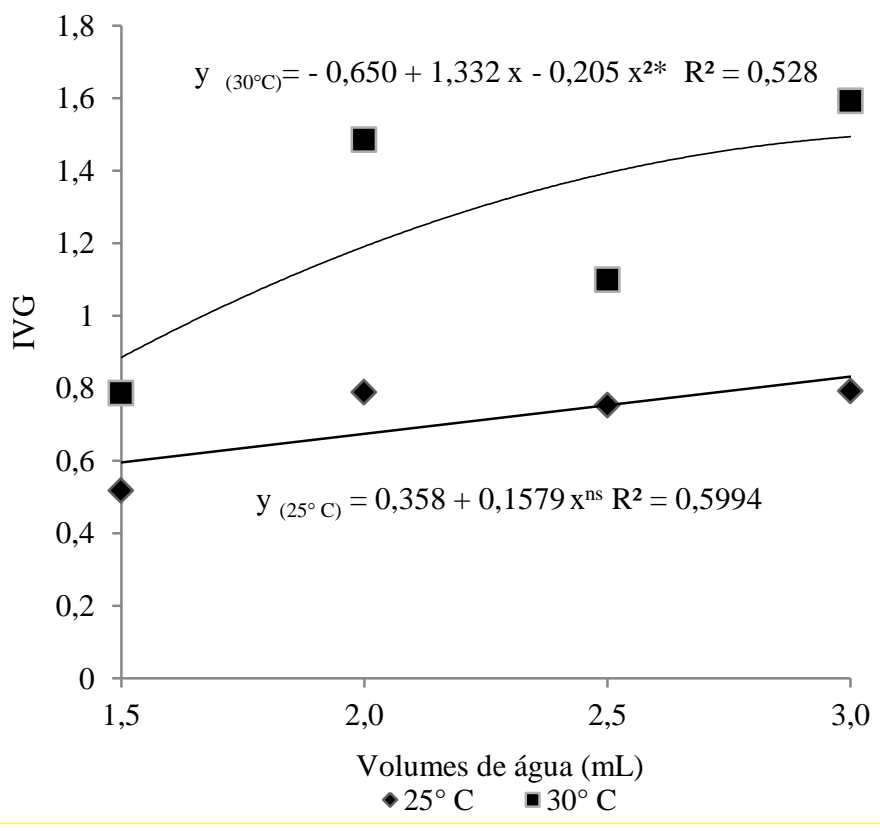

A porcentagem de sementes mortas (Figura 3) decresceu nas duas temperaturas com o aumento de volume de água adicionado ao substrato, isso caracteriza a exigência dessa espécie para maiores volumes de água para desencadear o processo de germinação como foi mostrado na Figura 1, onde se obteve maiores potenciais de germinação com o volume de
3,0 vezes o peso do papel seco nas duas temperaturas de 25 e $30^{\circ} \mathrm{C}$. Sendo válido destacar que nos menores volumes de água foi observado maior quantidade de sementes mortas, provavelmente, devido à quantidade de água ser insuficientes para dá início à germinação, aliada a limitação física do tegumento. 
Figura 3. Porcentagem de sementes mortas de Bixa orellana L. resultantes das diferentes temperaturas e volumes de água no substrato. ${ }^{* *}=\mathrm{P}<0,01$.

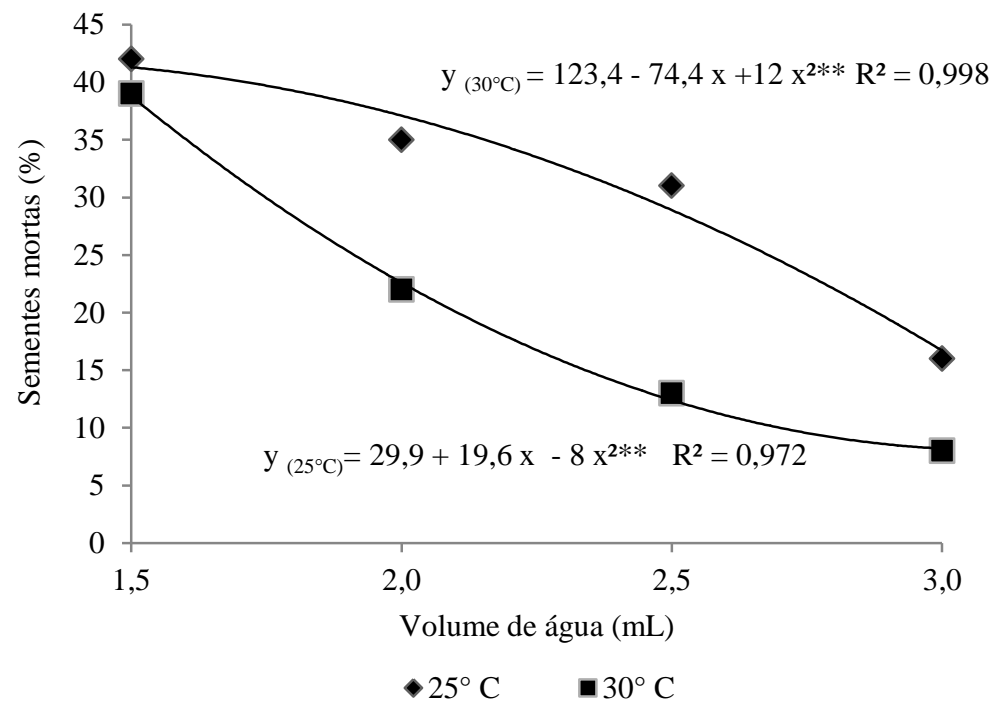

Conforme mostrado na figura 4 , podemos observar o crescimento das plântulas apresentou a tendência de maior desenvolvimento em função da temperatura e volume de água adicionado ao substrato, expressando melhor vigor, assim como observado no IVG, sendo mais uma vez observado os melhores resultados na temperatura $30^{\circ} \mathrm{C}$. Deve-se destacar que no volume de 1,5 vezes o peso do papel em ambas as temperaturas não ocorreu à medição de plântulas por não terem desenvolvido todas as suas estruturas para que fossem avaliadas.

Estes resultados corroboram com Azevedo et al. (2010), pois ao analisar as sementes de Crescentia cujete L. obtiveram resultados similares, onde as melhores temperaturas para proporcionar o maior desenvolvimento das plântulas (comprimento de parte aérea e da raiz) foi de $30^{\circ} \mathrm{C}$ e, Guedes et al. (2009) estudando a germinação de sementes de Cereus jamacaru DC., também sugeriu a temperatura de $30{ }^{\circ} \mathrm{C}$ como sendo a melhor para crescimento das plântulas.

De acordo com Nakagawa (1999), a diferença de $1{ }^{\circ} \mathrm{C}$ na temperatura durante o teste de germinação provavelmente, terá efeito baixo na porcentagem final de germinação, porém esta mesma diferença proporcionará considerável efeito no comprimento da raiz das plântulas. Estes resultados foram evidenciados no presente estudo, onde se observa que o comprimento da plântula foi crescente com o volume de água por tratamento (Figura 4), em especial a raiz primária, sendo que na temperatura de $30^{\circ} \mathrm{C}$ o maior valor foi observado no volume 3,0 vezes o peso do papel com $10,2 \mathrm{~cm}$, ficando evidente que houve mais influencia pela elevação da temperatura do que na porcentagem de germinação total (Figura 1).

Figura 4. Comprimento de plântulas oriundas de sementes de Bixa orellana L., submetidas a diferentes temperaturas e volumes de água no substrato. $* *=\mathrm{P}<0,01$.

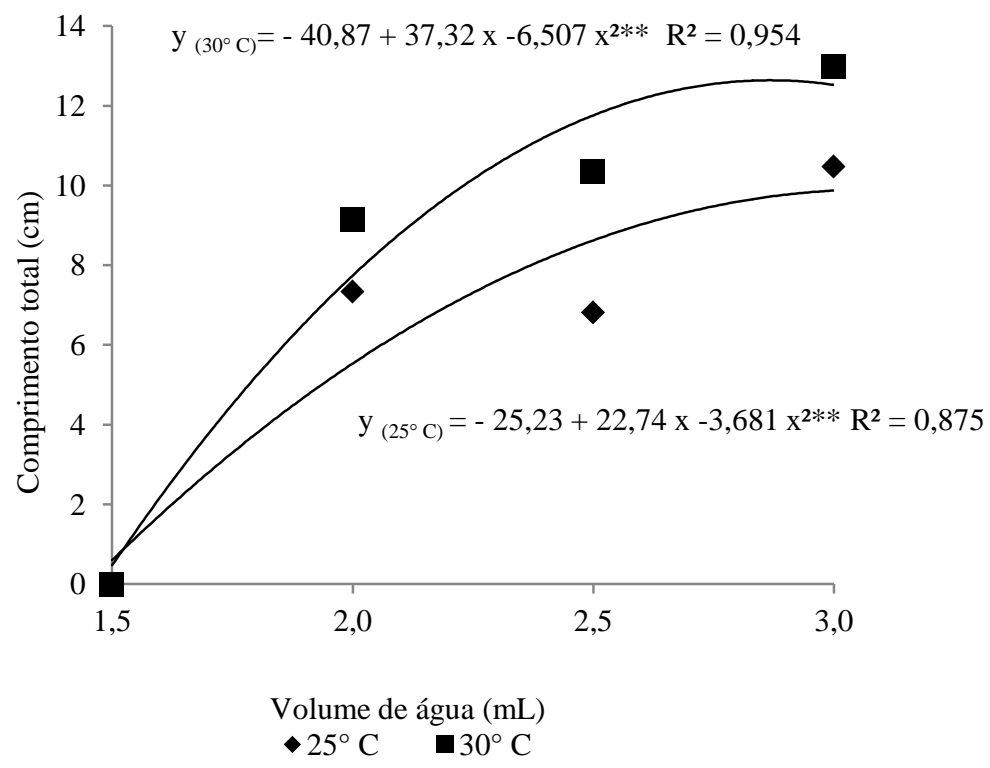

Na Figura 5 mostra que a massa seca de plântulas de $B$. temperatura de $30{ }^{\circ} \mathrm{C}$, entretanto houve um decréscimo a orellana L., aos 21 dias após a semeadura foi maior na partir do volume de 2,5 vezes o peso do papel. 
Figura 5. Massa seca de plântulas oriundas de sementes de Bixa orellana L., submetidas a diferentes temperaturas e volumes de água no substrato. ${ }^{* *}=\mathrm{P}<0,01$.

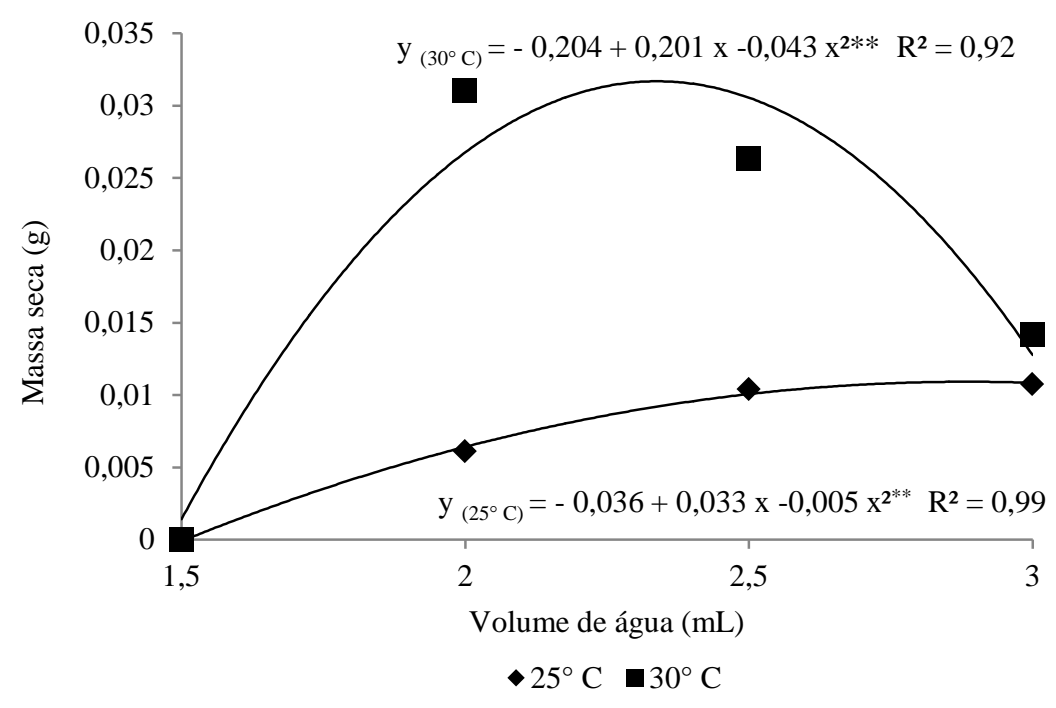

A massa seca de plântulas apresentou a tendência de aumento, proporcionalmente, em função da maior quantidade de água adicionada ao substrato para germinação quando mantida na temperatura de $25^{\circ} \mathrm{C}$, enquanto na de $30^{\circ} \mathrm{C}$ inicialmente foi observado acréscimo, seguido posteriormente de queda. Baseado em Dan et al. (1987), a explicação provável para a massa seca ter sido maior na temperatura de $30^{\circ} \mathrm{C}$ pode ser devido a semente expressar melhor o seu potencial nessa condição, influenciando diretamente na maior capacidade de transformação do suprimento de reserva dos tecidos de armazenamento e incorporação destes pelo eixo embrionário originando plântulas com maior taxa de crescimento.

Conforme os dados apresentados na Figura 5 pode-se inferir que adicionar quantidade de água superior a 2,5 vezes o peso seco do substrato poderá afetar negativamente o vigor das plântulas, quando avaliado através do teste de massa seca, baseando nisso e também devido as sementes serem pequenas os resultados sugerem não ultrapassar esse valor.

\section{CONCLUSÕES}

O potencial germinativo e o vigor é mais expressivo na temperatura de $30^{\circ} \mathrm{C}$.

$\mathrm{O}$ teste de massa seca sugere que quantidades de água superior a 2,5 vezes ao peso seco do substrato papel pode afetar negativamente o vigor.

Substrato pouco umedecido limita a germinação das sementes e consequentemente condiciona a maior porcentagem de sementes mortas.

\section{REFERÊNCIAS BIBLIOGRÁFICAS}

AMARAL, L.I.V.; PEREIRA, M. F. A.; CORTELAZZO, A. L. Quebra de dormência em sementes de Bixa orellana. Revista Brasileira de Fisiologia Vegetal, v.7, n.2, p.151157. 1995.
AZEVEDO, C.F.; BRUNO, R.L.A.; GONÇALVES, E.P.; QUIRINO, Z.G.M. Germinação de sementes de cabaça em diferentes substratos e temperaturas. Revista Brasileira Ciências Agrárias, Recife, v.5, n.3, p.354-357, 2010.

CASTRO, C. B.; MARTINS, C. S.; FALESI, I. C.; NAZARE, R. F. R.; KATO, O. H.; BENCHIMOL, R. L.; VENTURIERI, M. M. A Cultura do Urucum. $2^{\mathrm{a}}$. ed. Brasília: Embrapa Informação Tecnológica. 61p. 2009.

CUSTÓDIO, C.C.; MACHADO-NETO, N.B.; CASEIRO, R.F.;IKEDA, M. E BOMFIM, D.C. Germinação de sementes de urucum (Bixa orellana L.). Revista Brasileira de Sementes, 24, 1: 197-202. 2002.

COIMBRA, R.A.; TOMAZ, C.A.; MARTINS, C.C.; NAKAGAWA, J. Teste de germinação com acondicionamento dos rolos de papel em sacos plásticos. Revista Brasileira de Sementes, v.29, n.1, p.92-97, 2007.

CORLETT, F.M.F.; BARROS, A.C.S.A., VILLELA, F.A. Qualidade fisiológica de sementes de urucum em diferentes ambientes e embalagens. Revista brasileira de Sementes, 29,2: 149-158. 2007.

DAN, E.L.; MELLO, V.D.C.; WETZEL, C.T.; POPINIGIS, F.; ZONTA, E.P. Transferência de matéria seca como método de avaliação do vigor de sementes de soja. Revista Brasileira de Sementes, Brasília, v.9, n.3, p.45$55,1987$.

FRANCO, C. F. O.; SILVA, F. C.; FILHO, J. C.; NETO, M. B.; SÃO JOSÉ, A. R.; REBOUÇAS, T. N. H.; FONTINELLI, I. E. C. Urucuzeiro agronegócios de corantes naturais. João Pessoa: EMEPA-PB,120 p. 2002.

GUEDES, R.S.; ALVES, E.U.; GONÇALVES, E.P.; BRUNO, R.L.A.; BRAGA JÚNIOR, J.M.; MEDEIROS, 
M.S. Germinação de sementes de Cereus jamacaru DC., em diferentes substratos e temperaturas. Acta Scientiarum. Biological Sciences, Maringá, v.31, n.2, p.159-164, 2009.

GUEDES, R. S.; ALVES, E.U.; GONÇALVES, E.P.; VIANA, J.S.; FRANÇA, P.R.C.; LIMA, C.R. Umedecimento do substrato e temperatura na germinação e vigor de sementes de Amburana cearensis (All.) A.C. Smith. Revista Brasileira de Sementes, v. 32, n. 3 p. 116-122, 2010.

LOPES, J.C.; LIMA, R.V.; MACEDO, C.M.P. Germinação e vigor de sementes de urucu. Horticultura Brasileira, 26, 1: 19-25. 2008.

MAGUIRE, J. D. Speed of germination-aid in selection and evolution for seedling emergence and vigor. Crop Science, Madison, v. 2, n. 2, p. 176-177, 1962.

MARCOS FILHO, J. Fisiologia de sementes de plantas cultivadas. Piracicaba: FEALQ, 495p. 2005.

MENDES, A. M. S.; FIGUEIREDO, A. F.; SILVA, J. F. Crescimento e maturação dos frutos e sementes de urucum. Revista Brasileira de Sementes, Londrina, v. 28, n. 1, p. 133-141, 2006.

NAKAGAWA, J. Testes de vigor baseados no desempenho das plântulas. In: KRZYZANOWSKI, F.C.; VIEIRA, R.D.; FRANÇA NETO, J.B. (Ed.). Vigor de sementes: conceitos e testes. Londrina: ABRATES, p.1-24.1999.

PEREIRA, T. S. Caracterização de plântulas de Bixa orellana L. - urucu (Bixaceae). Revista Brasileira de Sementes, Brasília, DF, v. 17, n. 2, p. 243-248, 1995.
PICOLOTTO, D. R. N.; THEODORO, J.V.C.; DIAS, A. R.; THEODORO, G.F.; ALVES, C.Z.; Germinação de sementes de urucum em função de métodos de superação de dormência e temperaturas. Pesquisa Agropecuária Tropical, Goiânia, v. 43, n. 3, p. 232-238, jul/set. 2013.

RAMOS, M.B.P.; VARELA, V.P.; MELO, M.F.F. Influência da temperatura e da quantidade de água no substrato sobre a germinação de sementes de Ochroma pyramidale (Cav. Ex Lam.) Urban (pau-de-balsa). Acta Amazônica, v.36, n.1, p.103-106, 2006.

RAMOS, M.B.P.; VARELA, V.P.; MELO, M.F.F. Influência da temperatura e da água sobre a germinação de sementes de paricá (Schizolobium amazonicum Huber ex Ducke - Leguminosae - Caesalpinoideae).Revista Brasileira de Sementes, v.28, n.1, p.163-168, 2006.

SILVA, J. H. V.; SILVA, E.L.; FILHO, J.J.; RIBIERO, M.L.G.; COSTA, F.G.P. et al. Resíduo da semente de urucum (Bixa orellana L.) como corante da gema, pele, bico e ovário de poedeiras avaliado por dois métodos analíticos. Ciência e Agrotecnologia, Lavras, v. 30, n. 5, p. 988-994, 2006.

VARELA, V.P.; RAMOS, M.B.P.; MELO, M.F.F. Umedecimento do substrato e temperatura na germinação de sementes de angelim-pedra (Dinizia excelsa Ducke).Revista Brasileira de Sementes, v.27, n.2, p.130-135, 2005. 